\title{
Meta-Analysis of Safety and Efficacy of Different Radical Gastrectomy in the Treatment of Gastric Cancer
}

\author{
TIPENG ZHANG, JUNBAO LIU1, CHANGBIN LIU², QIJIE WANG ${ }^{3}$, YANLI BIAN AND CHENG WANG ${ }^{4 *}$ \\ Department of Clinical Medicine, Zhengzhou Shuqing Medical College, Zhengzhou, Henan 450064, ${ }^{1}$ Department of Traditional \\ Chinese Medicine, Henan Provincial People's Hospital, Zhengzhou, Henan 450008, ²Department of Traditional Chinese Medicine, \\ Hospital of Traditional Chinese Medicine, Cangzhou, Hebei 061000, ${ }^{3}$ Department of Gastroenterology, Zhengzhou Yangcheng Hospital, \\ Zhengzhou, Henan 452470, ${ }^{4}$ Zhengzhou Shuqing Medical College, Zhengzhou, Henan 450064, China
}

Zhang et al.: Radical Gastrectomy in the Treatment of Gastric Cancer

\begin{abstract}
To investigate the safety and efficacy of different radical gastric cancer treatments in the management of gastric cancer. The literature published in the last $5 \mathrm{y}$ was searched for recent outcomes of different radical gastric cancer procedures used in the treatment of gastric cancer. 14 papers were finally included according to the established screening criteria. The trial design, study population characteristics and findings of the included studies were abstracted using randomized independent trials and statistically analyzed using RevMan 5.0 software. The results of the meta-analysis showed that laparoscopic early distal gastric cancer surgery compared with conventional open surgery: The operative time was 49.85 min longer $(p<0.05)$, but intraoperative bleeding was $145.50 \mathrm{ml}$ less $(\mathbf{p}<\mathbf{0 . 0 5})$, the number of postoperative analgesic requests was 1.22 less $(p=0.01)$ and the number of days to the first postoperative vent was $0.57 \mathrm{~d}$ shorter $(\mathrm{p}<0.05)$, the number of days to the first postoperative meal was shortened by $0.88 \mathrm{~d}(\mathrm{p}<0.05)$; the number of postoperative hospital days was shortened by $4.76 \mathrm{~d}(\mathrm{p}<0.05)$ and the incidence of postoperative complications was low, both differences were statistically significant $(\mathbf{p}<\mathbf{0 . 0 5})$. The recent efficacy of laparoscopy-assisted distal gastrectomy in treating gastric cancer was significantly better than that of conventional open distal gastrectomy.
\end{abstract}

Key words: Gastric cancer, gastrectomy, laparoscopy, meta-analysis

With the rapid development of endoscopy technology and the general acceptance of endoscopy among high risk groups, more and more patients with early gastric cancer have received timely diagnosis and treatment. Due to the high 5 y survival rate of patients with early gastric cancer, minimally invasive and safe surgery to improve the quality of life of patients after surgery is of great significance. In 1991, Kitano et al. first carried out Laparoscopy-Assisted Distal Gastrectomy (LADG) for the treatment of early gastric cancer ${ }^{[1]}$. After nearly 20 $\mathrm{y}$ of development, the minimally invasive advantages of LADG compared to Conventional Open Distal Gastrectomy (CODG) in the treatment of early distal gastrectomy have become more obvious. In this study, we studied the literature published in recent years about the recent efficacy of LADG vs. CODG and performed a meta-analysis to further prove the safety and feasibility of laparoscopic early distal gastric cancer surgery.

\section{MATERIALS AND METHODS}

Research type and object:

In recent years, we searched complete laparoscopic radical gastric cancer surgery and laparoscopic-assisted radical gastric cancer surgery (Randomized Controlled Trial (RCT), retrospective observational research, Retrospective Non-Randomized Trial (RNT)).

\section{Literature inclusion criteria:}

Documents that meet the following requirements will be the research objects of this article: The published English documents of CODG and LADG surgical comparative studies, RCT and RNT can be selected; The research data provides a clear number of patients, case selection criteria, description of the grouping method and contains at least 2 relevant analysis data; The selected literature must clearly record that the operation method is fully laparoscopic and laparoscopically assisted; For the original data of relevant literature, continuous variables should provide mean and standard deviation; binary variables should provide combined Odds Ratio (OR) value and $95 \%$ Confidence Interval (CI) or can be converted into OR value and its $95 \%$ CI regression coefficient and its standard error; For the literature of the same unit, select the literature of higher quality or

*Address for correspondence

E-mail: ym04161564@163.com 
the most recently published literature for statistics; The original text must be published in English and other languages will not be included.

\section{Literature exclusion criteria:}

The following documents were not included in this study: No CODG or LADG in the surgical method; Cases of hand-assisted laparoscopic radical gastric cancer surgery included in laparoscopic surgery; Cases of other surgical diseases included in the selected cases; The selected cases contain palliative gastric cancer surgery cases; Historical control and other non-contemporaneous controlled research literature; This study does not require the patient's disease stage, surgical resection range, and lymph node dissection range, but excludes two, the group has obvious grouping tendency or significantly different results in the disease stage or the scan range of the lymph node.

\section{Evaluation of the quality of literature:}

This article uses the "*" symbol method to evaluate the quality of the selected documents ${ }^{[2]}$. There are a total of 11 evaluation indicators. The data of each evaluation indicator of all selected documents are extracted. If one of the evaluation indicators is met, it will be $1 *$. If all 11 evaluation indicators of the selected documents are met, $11^{*}$ will be awarded; if 1 document is* the number reaches the total number of $*>50 \%$, the quality is considered to be better.

\section{Data extraction:}

Three experts with rich professional knowledge background use a unified data table to extract data and vote by show of hands in case of dispute. The content of the extracted data includes: Publication time, first author, disease period, number of patients, surgical operation time, intraoperative blood loss, range of lymph node dissection, number of lymph node dissection, distance between proximal and distal resection edges, intestinal tract. The time of the first exhaust after the operation, the time of the first liquid intake after the operation and the length of the patient's hospital stay.

\section{Statistical analysis:}

In this meta-analysis, the Review Manager 5.2 statistical software provided by the Cochrane Collaboration was used for analysis and the data were merged and tested for heterogeneity. If the data has no obvious heterogeneity $\left(\mathrm{I}^{2} \leq 50 \%\right)$, the fixed effects model can be used. If the data is heterogeneous $\left(\mathrm{I}^{2}>50 \%\right)$, the random effects model must be used to calculate the combined effect size. For binary variables, we use Relative Risk (RR), while for continuous variables with the same unit of measurement, we use the Weighted Mean Difference (WMD) and for continuous variables with different units of measurement, we use the Standardized Mean Difference (SMD), each effect size is represented by a $95 \%$ CI.

\section{Evaluation of the quality of selected documents:}

A total of 14 studies comparing the short-term efficacy of LADG and CODG were selected ${ }^{[3-16]}$. Since there are only 4 relevant RCTs and they are all small sample studies $^{[3-6]}$. Considering that the sample size is also an important factor affecting the results, this study also included 10 RNTs to make up for the simple. The disadvantage of insufficient sample size of $\mathrm{RCT}^{[7-16]}$. The selected documents are all $>6^{*}$. As shown in Table 1 .

Descriptive analysis of the characteristics of all included studies:

There were 27 cases with the smallest sample size ${ }^{[12]}$ and 211 cases with the largest sample size ${ }^{[10]}$. The total sample size of the whole study was 1394 cases, 755 cases were in the LADG group and 639 cases were in the CODG group. Wing checked that all the selected studies were in full compliance with the selection criteria. The characteristics of all studies are shown in Table 2 and fig. 1.

TABLE 1: EVALUATION OF THE QUALITY OF SELECTED DOCUMENTS

\begin{tabular}{|c|c|c|c|c|c|c|c|c|c|c|c|c|c|}
\hline \multirow[t]{2}{*}{ Author } & \multirow[t]{2}{*}{ Year } & \multicolumn{3}{|c|}{ Literature design } & \multicolumn{6}{|c|}{ Comparison index of two surgical methods } & \multicolumn{2}{|c|}{$\begin{array}{l}\text { Postoperative } \\
\text { follow-up status }\end{array}$} & \multirow{2}{*}{$\begin{array}{c}\text { Total* } \\
\text { number }\end{array}$} \\
\hline & & 1 & 2 & 3 & 4 & 5 & 6 & 7 & 8 & 9 & 10 & 11 & \\
\hline Zheng et al. & 2016 & & $*$ & * & $*$ & * & * & * & * & * & * & * & 10 \\
\hline Wang et al. & 2020 & & & & $*$ & * & * & * & & * & * & & 6 \\
\hline Chen et al. & 2020 & & $*$ & & $*$ & * & * & & * & * & * & * & 8 \\
\hline Yoshida et al. & 2018 & * & * & & * & * & * & * & * & * & * & * & 10 \\
\hline
\end{tabular}




\begin{tabular}{|c|c|c|c|c|c|c|c|c|c|c|c|c|c|}
\hline Kim et al. & 2019 & & * & & * & * & * & & * & * & * & * & 8 \\
\hline Li et al. & 2019 & & * & * & * & * & * & * & & * & * & * & 9 \\
\hline Katai et al. & 2020 & * & * & & * & * & * & & * & * & * & * & 9 \\
\hline Chen et al. & 2017 & * & * & & * & * & * & * & * & * & * & & 9 \\
\hline Wang et al. & 2019 & & * & & * & * & * & * & * & * & & & 7 \\
\hline Li et al. & 2018 & & * & * & * & * & * & * & & * & * & * & 9 \\
\hline Qiu et al. & 2019 & & * & * & * & * & * & * & & * & * & & 8 \\
\hline Beyer et al. & 2019 & & * & * & * & * & * & & * & & * & & 7 \\
\hline Yamada et al. & 2020 & * & * & * & * & * & * & & * & * & * & & 9 \\
\hline Zhou et al. & 2020 & & * & * & * & * & * & & * & * & & * & 8 \\
\hline
\end{tabular}

Note: Literature design: (1) Whether the literature is a randomized controlled study, if it is $1^{*}$, if it isn't, none; (2) Whether it has the inclusion criteria, if it is $1^{*}$, if it isn't, none; (3) Sample size >100 cases $1^{*},<100$ cases, none; (4) Age; (5) Gender; (6) Tumor location; (7) Tumor size; (8) Record tumor stage or depth of invasion, compare the above indicators in 4, 5, 6, 7 and 8 between the two operations. If the difference is not statistically significant, give $1^{*}$, if it is statistically significant or not described none; (9) If you record the operation time, intraoperative blood loss, the number of times analgesics are required after the operation, the first postoperative days of exhaust, the first postoperative days of eating and the postoperative hospitalization days, 4 items will be $1^{*}$, if not postoperative follow-up; (10) Complications, if described, $1^{*}$, if not described, none; (11) Mortality, recurrence, 5 -year survival rate, if one item or more than one item is recorded $1^{*}$, if none of the three is recorded none

TABLE 2: DESCRIPTIVE ANALYSIS OF THE CHARACTERISTICS OF ALL INCLUDED STUDIES

\begin{tabular}{|c|c|c|c|c|c|c|}
\hline \multirow{2}{*}{ Author } & \multirow{2}{*}{ Year } & \multirow{2}{*}{ Design } & \multicolumn{2}{|c|}{$\mathrm{N}$} & \multirow{2}{*}{$\begin{array}{c}\text { Patient } \\
\text { characteristics }\end{array}$} & \multirow{2}{*}{ Research index } \\
\hline & & & LADG & CODG & & \\
\hline Zheng et al. & 2016 & RNT & 49 & 53 & ABEF & 12345678 \\
\hline Wang et al. & 2020 & RNT & 21 & 31 & ABEF & 12345678 \\
\hline Chen et al. & 2020 & RNT & 24 & 35 & ABDEF & 12345678 \\
\hline Yoshida et al. & 2018 & $\mathrm{RCT}$ & 14 & 14 & ABDEF & 1234567 \\
\hline Kim et al. & 2019 & RNT & 10 & 17 & ABDF & 12467 \\
\hline Li et al. & 2019 & $\mathrm{RCT}$ & 14 & 14 & ABCE & 12345678 \\
\hline Katai et al. & 2020 & RNT & 71 & 76 & $A B C D E$ & 135678 \\
\hline Chen et al. & 2017 & $\mathrm{RCT}$ & 24 & 23 & ABDEF & 1234567 \\
\hline Wang et al. & 2019 & RNT & 89 & 60 & ABDEF & 1267 \\
\hline Li et al. & 2018 & RNT & 20 & 22 & ABDE & 123456 \\
\hline Qiu et al. & 2019 & RNT & 120 & 30 & $A B C$ & 123467 \\
\hline Beyer et al. & 2019 & RNT & 87 & 101 & $A B C D$ & 127 \\
\hline Yamada et al. & 2020 & $\mathrm{RCT}$ & 82 & 82 & $A B C D E$ & 123467 \\
\hline Zhou et al. & 2020 & RNT & 130 & 81 & ABCDEF & 1268 \\
\hline
\end{tabular}

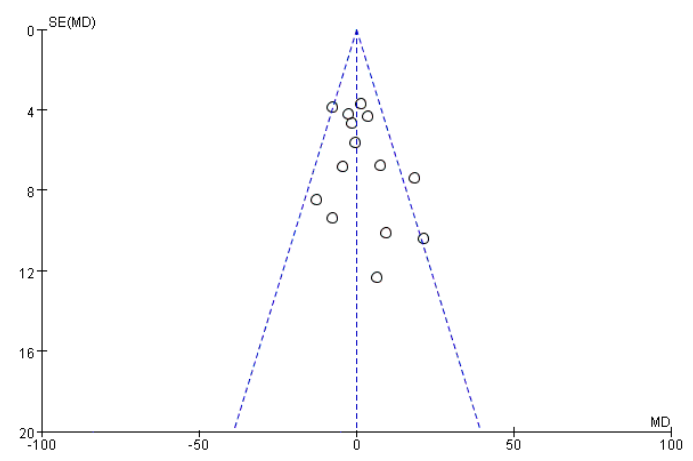

Fig. 1: Meta-analysis funnel chart 
Meta-analysis of operation time comparison:

A total of 14 studies compared the operation time of LADG and CODG were included in this meta-analysis sample size of 1394 cases. Among them, 4 RCTs and 5 RNTs considered that the operation time of LADG was longer than that of CODG was statistically significant; the remaining 5 RNTs considered that the operation time of LADG and CODG was similar and the difference was not statistically significant. The meta-analysis results showed that the operation time of LADG was $49.85 \mathrm{~min}$ longer than that of CODG $(\mathrm{p}<0.05)$ and the difference was statistically significant, as shown in fig. 2.

Meta-analysis of intraoperative blood loss comparison:

A total of 13 studies comparing the intraoperative blood loss of LADG and CODG were included in this meta-analysis, with a sample size of 1247 cases. Among them, 2 RCTs and 8 RNTs believed that LADG had less intraoperative blood loss than CODG and the difference was statistically significant; the remaining 3 RNTs believed that LADG and CODG had similar intraoperative blood loss and the difference was not statistically significant; the results of meta-analysis showed, intraoperative blood loss of LADG was $97.50 \mathrm{ml}$ less than CODG $(\mathrm{p}<0.05)$ and the difference was statistically significant, as shown in fig. 3 .

\section{Meta-analysis of the number of times required for postoperative analgesics:}

A total of 7 studies comparing LADG and CODG's required number of postoperative analgesics were included in this meta-analysis, with a sample size of 605 cases. Among them, 2 RNT considered that the number of requests for analgesics after LADG was less than CODG and the difference was statistically significant; the remaining 3 RCTs and 2 RNT considered that the number of requests for analgesics after LADG and CODG was similar and the difference was not statistically significant. Meta-analysis results showed that the number of analgesics required after LADG was 1.22 times lower than that of CODG $(p=0.01)$ and the difference was statistically significant, as shown in fig. 4.

\section{Meta-analysis of the number of days after the first exhaust:}

A total of 10 studies comparing LADG and CODG postoperative days of the first exhaust were included in this meta-analysis, with a sample size of 829 cases. Among them, 3 RCTs and 4 RNT considered that the first exhaust days after LADG were shorter than CODG and the difference was statistically significant; the remaining 1 RCT and 2 RNT considered that the first exhaust days after LADG and CODG were similar. The difference was not statistically significant; the results of meta-analysis showed that the first exhaust days after LADG was 0.57 $\mathrm{d}$ shorter than that of CODG $(\mathrm{p}<0.05)$ and the difference was statistically significant, as shown in fig. 5 .

\section{Meta-analysis of the number of days after the first meal:}

A total of 10 studies comparing LADG and CODG's first eating days after surgery were included in this metaanalysis, with a sample size of 699 cases. Among them, 2 RCTs and 5 RNTs considered that the first feeding days after LADG were shorter than CODG and the difference was statistically significant; the remaining 2 RCTs and 1 RNT considered that the first feeding days after LADG and CODG were similar and there was no difference. Statistical significance; meta-analysis results showed that the first feeding days after LADG was $0.88 \mathrm{~d}$ shorter than CODG $(\mathrm{p}<0.05)$ and the difference was statistically significant, as shown in fig. 6 .

\section{Meta-analysis of postoperative hospital stay:}

A total of 13 studies compared the length of hospital stay after LADG and CODG were included in this metaanalysis sample size of 1206 cases. Among them, 2 RCTs and 7 RNTs considered that the postoperative hospital stay of LADG was less than that of CODG and the difference was statistically significant; the remaining 2 RCTs and 2 RNTs considered that the postoperative hospital stays of LADG and CODG were similar and there was no statistically significant difference; Meta-analysis results showed that the postoperative hospital stay of LADG was $4.76 \mathrm{~d}$ shorter than that of CODG $(\mathrm{p}<0.05)$ and the difference was statistically significant, as shown in fig. 7 .

\section{Meta-analysis of the incidence of postoperative complications:}

A total of 12 studies compared the incidence of complications after LADG and CODG were included in this meta-analysis, with a sample size of 1113 cases. The results of the meta-analysis showed that the postoperative complication rates of LADG and CODG were $7.95 \%$ and $16.86 \%$ respectively and the difference was statistically significant $(\mathrm{p}<0.05)$, as shown in fig. 8 .

\section{Meta-analysis of postoperative mortality:}

A total of 6 studies compared the postoperative mortality of LADG and CODG were included in this meta-analysis, with a sample size of 599 cases (including 3 studies due to the postoperative mortality of the LADG group and the CODG group all are 0 , so they are excluded from this meta-analysis). The results of the meta-analysis showed that the postoperative mortality of LADG and CODG were $2.91 \%$ and $1.72 \%$ respectively and the difference was not statistically significant $(\mathrm{p}=0.74)$, as shown in fig. 9 . 


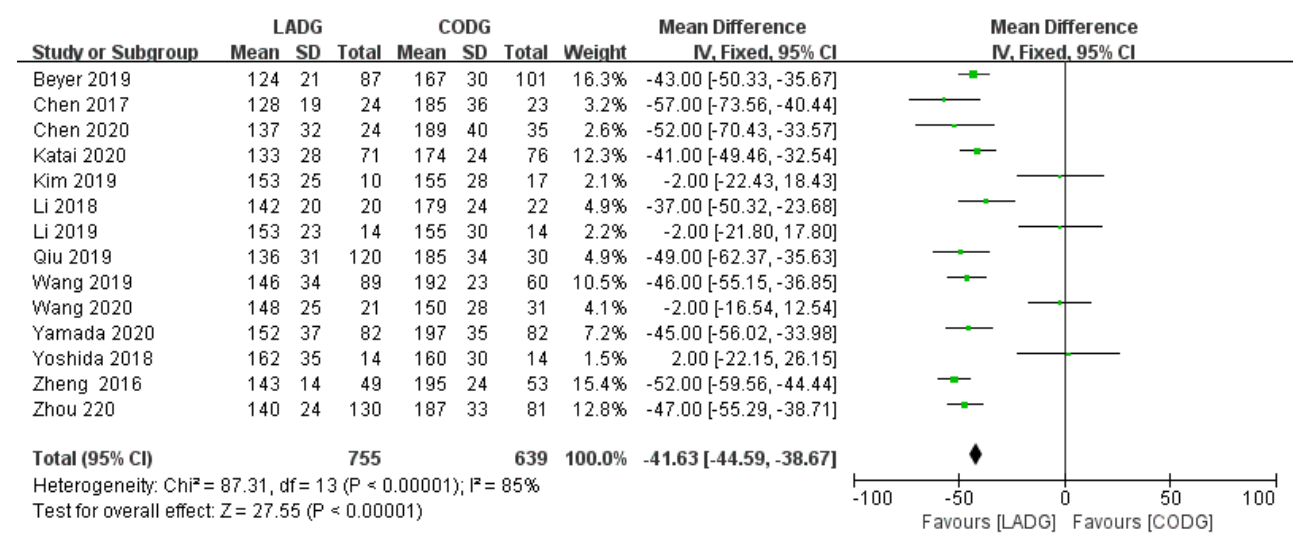

Fig. 2: Comparison of operation time

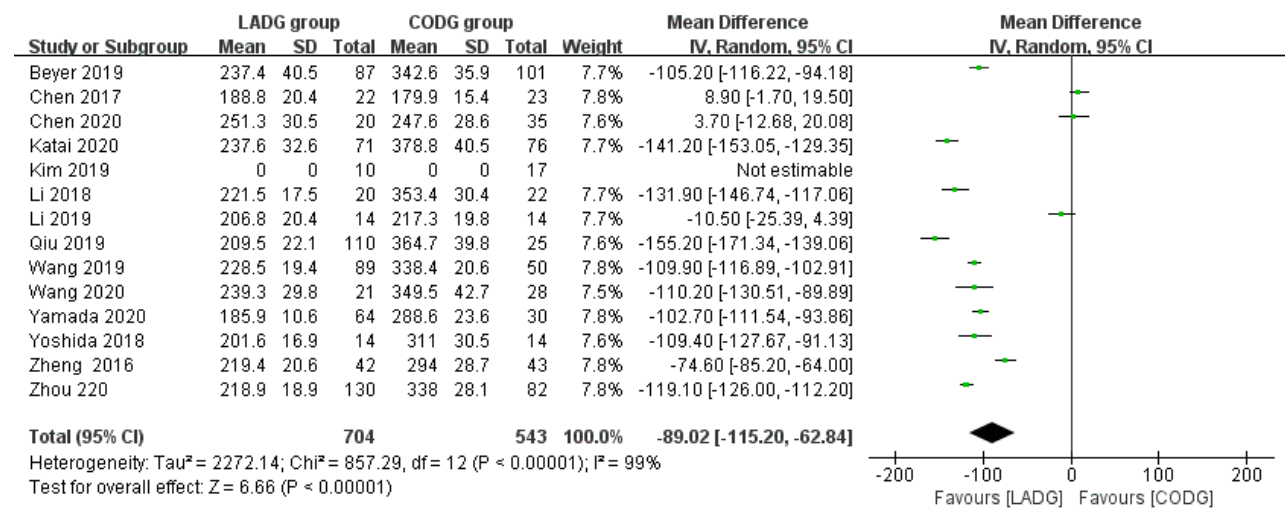

Fig. 3: Comparison of intraoperative blood loss

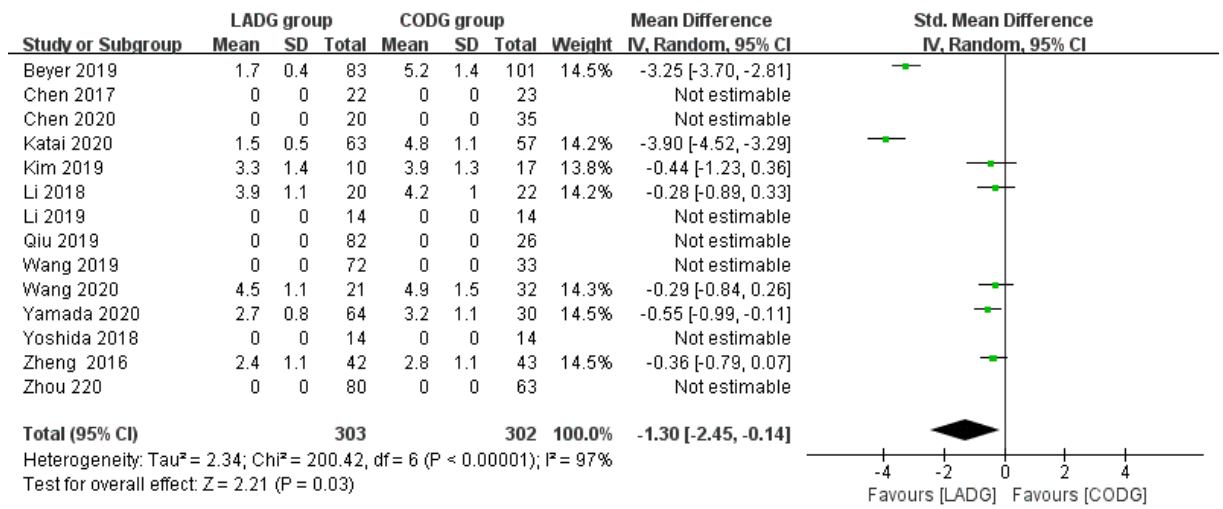

Fig. 4: Comparison of the number of required analgesics after surgery

\begin{tabular}{|c|c|c|c|c|c|c|c|c|c|c|c|}
\hline \multirow[b]{2}{*}{ Studv or Subgroup } & \multicolumn{3}{|c|}{ LADG group } & \multicolumn{3}{|c|}{ CODG group } & \multicolumn{2}{|r|}{ Std. Mean Difference } & \multirow{2}{*}{\multicolumn{3}{|c|}{$\begin{array}{l}\text { Std. Mean Difference } \\
\text { IV. Random, } 95 \% \mathrm{Cl}\end{array}$}} \\
\hline & Mean & SD & Total & Mean & SD & Total & Weight & N. Random, $95 \% \mathrm{Cl}$ & & & \\
\hline Beyer 2019 & 0 & 0 & 83 & 0 & 0 & 101 & & Not estimable & & & \\
\hline Chen 2017 & 0 & 0 & 22 & 0 & 0 & 23 & & Not estimable & & & \\
\hline Chen 2020 & 5.1 & 0.8 & 20 & 5.7 & 1.1 & 35 & $10.2 \%$ & $-0.59[-1.15,-0.03]$ & & $\Rightarrow$ & \\
\hline Katai 2020 & 4.5 & 1.2 & 63 & 10.5 & 1.8 & 57 & $10.1 \%$ & $-3.94[-4.56,-3.32]$ & $=$ & & \\
\hline Kim 2019 & 0 & 0 & 10 & 0 & 0 & 0 & & Not estimable & & & \\
\hline Li 2018 & 5.3 & 1 & 20 & 5.6 & 1.3 & 22 & $10.2 \%$ & $-0.25[-0.86,0.36]$ & & 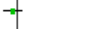 & \\
\hline Li 2019 & 4.8 & 0.7 & 14 & 5 & 0.9 & 14 & $10.0 \%$ & $-0.24[-0.98,0.50]$ & & & \\
\hline Qiu 2019 & 4.8 & 0.9 & 82 & 11 & 1.4 & 26 & $9.9 \%$ & $-5.92[-6.84,-5.00]$ & $\rightarrow$ & & \\
\hline Wang 2019 & 4.9 & 0.6 & 72 & 10.5 & 1.3 & 33 & $9.8 \%$ & $-6.32[-7.29,-5.36]$ & $\rightarrow$ & & \\
\hline Wang 2020 & 4.3 & 1.6 & 21 & 12.5 & 1.1 & 28 & $9.3 \%$ & $-6.04[-7.41,-4.67]$ & & & \\
\hline Yamada 2020 & 4.7 & 2.1 & 64 & 9.9 & 2.7 & 30 & $10.2 \%$ & $-2.24[-2.78,-1.69]$ & $=$ & & \\
\hline Yoshida 2018 & 0 & 0 & 14 & 0 & 0 & 14 & & Not estimable & & & \\
\hline Zheng 2016 & 4.3 & 1.3 & 42 & 10.6 & 1.9 & 43 & $10.1 \%$ & $-3.83[-4.55,-3.10]$ & $=$ & & \\
\hline Zhou 220 & 3.9 & 1.3 & 80 & 11.5 & 3.3 & 63 & $10.2 \%$ & $-3.16[-3.65,-2.66]$ & - & & \\
\hline Total $(95 \% \mathrm{Cl})$ & & & 478 & & & 351 & $100.0 \%$ & $-3.21[-4.48,-1.94]$ & & & \\
\hline $\begin{array}{l}\text { Heterogeneity: Tau } \\
\text { Test for overall effect }\end{array}$ & $\begin{array}{l}4.01 ; \mathrm{Cl} \\
Z=4.97\end{array}$ & $\begin{array}{l}\mathrm{l}^{2}=3 \\
(P<0\end{array}$ & $\begin{array}{l}12.29, \\
0.0000\end{array}$ & & & 0001); & $\left.\right|^{2}=97 \%$ & & $\begin{array}{cc}1 & 1 \\
-10 & -5 \\
& \text { Favours [LADG] }\end{array}$ & $\begin{array}{cr}0 & 1 \\
0 & 0 \\
3] & \text { Favours [ }\end{array}$ & $\begin{array}{c}10 \\
G]\end{array}$ \\
\hline
\end{tabular}

Fig. 5: Comparison of the first exhaust days after operation 


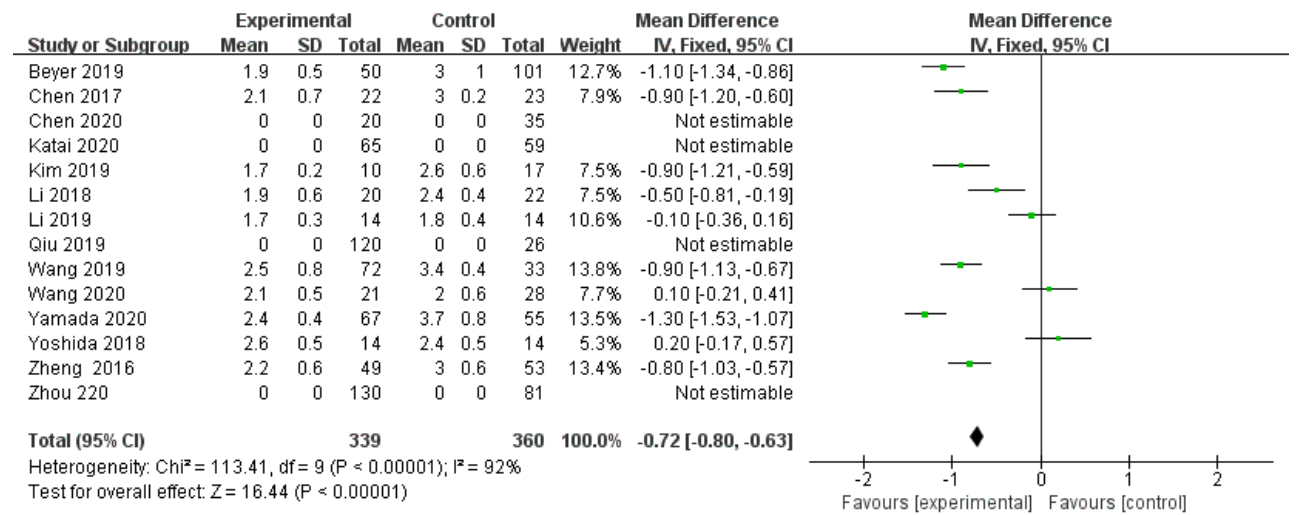

Fig. 6: Comparison of the number of days after the first eating

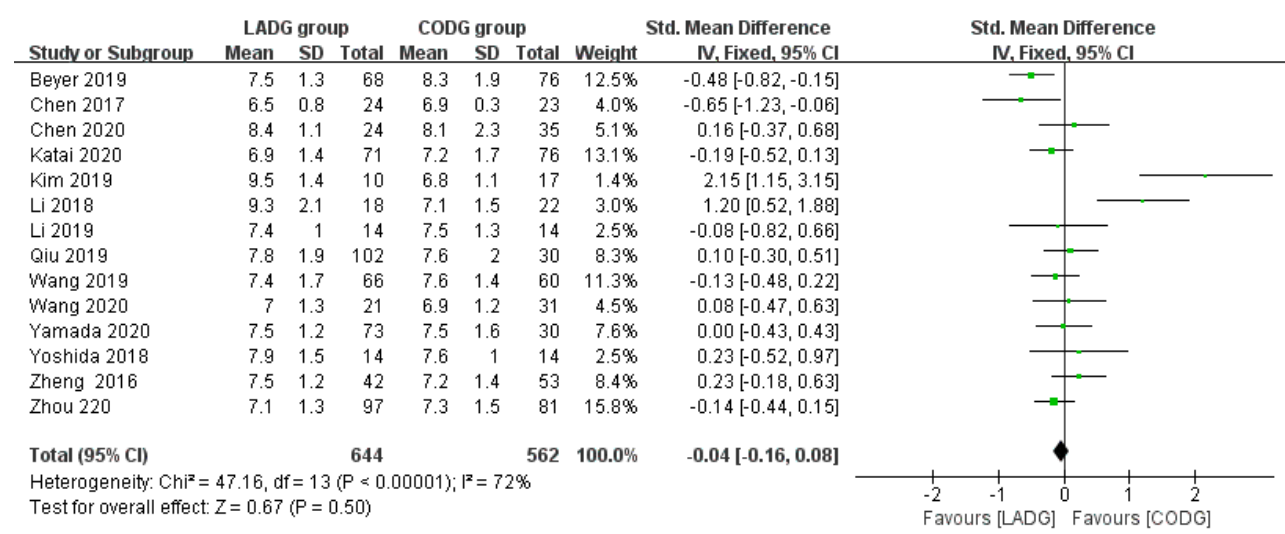

Fig. 7: Comparison of the postoperative hospital stay

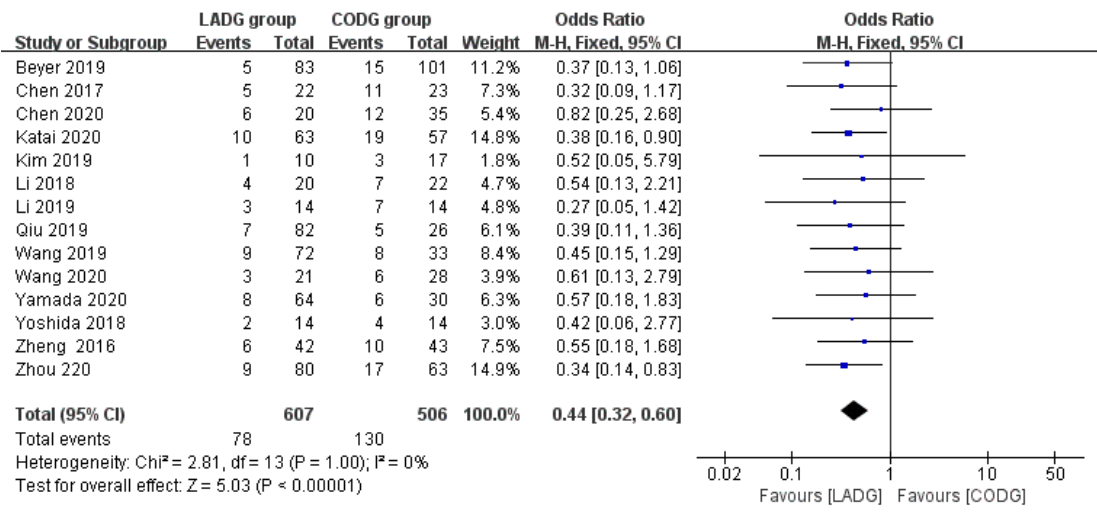

Fig. 8: Comparison of the postoperative complications

\begin{tabular}{|c|c|c|c|c|c|c|c|c|c|c|}
\hline Studv or Subgroup & $\begin{array}{l}\text { LADG } \\
\text { Events }\end{array}$ & Iotal & $\begin{array}{l}\text { CODC } \\
\text { Events }\end{array}$ & & Weight & $\begin{array}{c}\text { Odds Ratio } \\
\text { M-H, Fixed, } 95 \% \mathrm{Cl}\end{array}$ & & $\begin{array}{r}\text { Odds } \\
\text { M-H, Fixe }\end{array}$ & $\begin{array}{l}\text { Ratio } \\
\text { ed, } 95 \% \mathrm{Cl}\end{array}$ & \\
\hline Beyer 2019 & 1 & 87 & 2 & 101 & & Not estimable & & & & \\
\hline Chen 2017 & 0 & 24 & 0 & 23 & & Not estimable & & & & \\
\hline Chen 2020 & 0 & 24 & 0 & 35 & & Not estimable & & & & \\
\hline Katai 2020 & 2 & 71 & 3 & 76 & $62.6 \%$ & $0.71[0.11,4.35]$ & & & & \\
\hline Kim 2019 & 0 & 10 & 0 & 17 & & Not estimable & & & & \\
\hline Li 2018 & 0 & 20 & 0 & 22 & & Not estimable & & & & \\
\hline Li 2019 & 0 & 14 & 0 & 14 & & Not estimable & & & & \\
\hline Qiu 2019 & 1 & 120 & 0 & 30 & $17.5 \%$ & $0.77[0.03,19.26]$ & & & & \\
\hline Wang 2019 & 0 & 89 & 0 & 60 & & Not estimable & & & & \\
\hline Wang 2020 & 0 & 21 & 0 & 31 & & Not estimable & & & & \\
\hline Yamada 2020 & 0 & 82 & 0 & 82 & & Not estimable & & & & \\
\hline Yoshida 2018 & 0 & 14 & 0 & 14 & & Not estimable & & & & \\
\hline Zheng 2016 & 1 & 45 & 1 & 53 & $20.0 \%$ & $1.18[0.07,19.45]$ & & & & \\
\hline Zhou 220 & 0 & 130 & 0 & 81 & & Not estimable & & & & \\
\hline Total $(95 \% \mathrm{Cl})$ & & 349 & & 250 & $100.0 \%$ & $0.81[0.20,3.21]$ & & & & \\
\hline Total events & 4 & & 4 & & & & & & & \\
\hline $\begin{array}{l}\text { Heterogeneity: } \mathrm{Ch}^{2} \\
\text { Test for overall effec }\end{array}$ & $\begin{array}{l}.09, \mathrm{df}=2 \\
=0.30\langle\mathrm{P}\end{array}$ & $\begin{array}{l}2(P=0 \\
=0.77\end{array}$ & $1.95) ; 1^{2}=$ & & & & & 0.1 & & 10 \\
\hline
\end{tabular}

Fig. 9: Comparison of the postoperative mortality 


\section{DISCUSSIONS}

Although laparoscopic radical surgery for early gastric cancer has become increasingly mature and has achieved good results, it has been listed as one of the standard treatment options for stage I gastric cancer by the 2002 Japanese Gastric Cancer Treatment Protocol ${ }^{[1]}$. However, many studies believe that laparoscopic surgery is in terms of operating time. There is no obvious advantage. In a prospective comparative analysis of 24 cases of LADG and 23 cases of CODG, Yoshida et al. concluded that the operation time of the LADG group was longer than that of the CODG group and the difference was statistically significant ${ }^{[6]}$. The retrospective studies of many scholars also believe that the operation time of the LADG group is longer than that of CODG. Yao et al. conducted a prospective analysis of 47 cases of LADG and concluded that although LADG has reached a certain level of technology in the treatment of early distal gastric cancer, it is still a time-consuming surgical procedure. On the one hand, because laparoscopic radical gastric cancer surgery requires multi-directional and multi-level anatomical separation of the perigastric space and extensive removal of the perigastric lymph nodes, most of the lymph nodes are located around important large blood vessels, making the operation difficult significant increase and prolong the operation time. On the other hand, because most surgeons are still in the "learning curve" of laparoscopic surgery, the "learning curve" is also one of the important factors affecting the operation time ${ }^{[17]}$. The results of this study also showed that the operation time of the LADG group was longer than that of the CODG group. However, with the widespread development of laparoscopic early gastric cancer surgery, the surgeon's familiarity with the level of laparoscopic anatomy, the improvement of surgical skills, the accumulation of experience and the improvement of surgical instruments, the operation time will be shortened. We compare the operation time of laparoscopic early gastric cancer surgery from the same center at different times. It can be seen that the operation time in the latter phase of the study is significantly shorter than that in the previous phase. Hyung et al. analyzed the operation time of LADG for early distal gastric cancer in 2005 and 2008 respectively ${ }^{[18]}$ and the results showed that the operation time of LADG in 2005 was $319 \mathrm{~min}$ and in 2008 it was shortened to $285.8 \mathrm{~min}$. Li et al. showed in the study on the "learning curve" that the operation time of each group of LADG gradually shortened with the increase of the number of cases, the operation time of 1-20 cases group was 351.2 min and the operation time of 41-60 cases group was shortened to $280.8 \mathrm{~min}$, the $81-100$ cases group was $221.6 \mathrm{~min}^{[19]}$. Therefore, although the operation time of laparoscopic early distal gastric cancer surgery is longer than that of traditional open surgery, with the continuous improvement of laparoscopic surgeons and the smooth passage of the "learning curve", the operation time will gradually shorten.

Laparoscopic surgery has changed the traditional operation method. It uses TV images to clearly magnify the real object several times, the operation field is clear, the blood vessel treatment is fine and the blindness of the operation is greatly reduced; coupled with the application of advanced hemostatic instruments such as ultrasonic knife, significantly reduces the amount of bleeding. In addition, the lighting used can reach the surgical site deeply, the surgeon's hands do not need to enter the patient's abdominal cavity and there is no need to separate tissues extensively, which greatly reduces the damage to the abdominal organs and interference with their functions, so that the patient's postoperative pain is reduced and recovered. The time is shortened, showing its minimally invasive advantages. In 1997, Goh et al. reported the results of a survey of 16 surgeons in 12 countries $^{[20]}$. Among them, 10 surgeons believed that LADG was superior to CODG because patients treated with laparoscopic surgery had a faster postoperative recovery, less pain and beautiful appearance. Kim et al. conducted a randomized controlled analysis of 164 cases of early-stage distal gastric cancer ${ }^{[7]}$. The results showed that LADG compared with CODG reduced intraoperative blood loss by $155.6 \mathrm{ml}$, shortened the first postoperative gastric days by $0.2 \mathrm{~d}$ and shortened the first postoperative feeding $0.4 \mathrm{~d}$, the length of hospital stay was shortened by $1.4 \mathrm{~d}$ and the difference between the two was statistically significant. The results of the meta-analysis of this study also confirmed that LADG has advantages over CODG in terms of surgical trauma, postoperative gastrointestinal function recovery and hospital stay.

Laparoscopic surgery not only has the advantages of minimally invasive surgery, many scholars believe that its postoperative complications rate is also significantly lower than traditional open surgery. Lee et al. retrospectively analyzed 106 cases of LADG and 105 cases of $\mathrm{CODG}^{[18]}$. The results showed that the postoperative complication rate was $4.7 \%$ in the LADG group and $13.3 \%$ in the CODG group and the difference was statistically significant. Lin et al. ${ }^{[21]}$ conducted a retrospective comparative analysis of 87 cases of LADG and 101 cases of CODG and showed 
that the incidence of postoperative complications in the LADG group was higher than that of Kitano et al. randomly compared the incidence of complications in 14 cases of LADG and 14 cases of CODG and found that, the incidence of complications in the two groups was similar. Chen et al. ${ }^{[10]}$ conducted a retrospective comparative analysis of 211 patients with early-stage distal gastric cancer and showed that the mortality of the LADG group and the CODG group were similar and the difference was not statistically significant. The results of the meta-analysis of this study showed that the incidence of postoperative complications in the LADG group was significantly lower than that in the CODG group and the mortality rate of the two groups was similar $^{[22]}$.

From the results of the meta-analysis of this study, the short-term efficacy of LADG in the treatment of gastric cancer is significantly better than that of CODG, but it still needs to be further proved by a large-sample, multi-center, prospective randomized controlled study.

\section{Acknowledgements:}

This work was supported by the Zhengzhou Shuqing Medical College and Henan Provincial People's Hospital.

\section{Authors' contributions:}

Tipeng Zhang and Junbao Liu have contributed equally to this work.

\section{Conflicts of interest:}

The authors declared no conflicts of interest.

\section{REFERENCES}

1. Kitano S, Iso Y, Moriyama M, Sugimachi K. Laparoscopyassisted Billroth I gastrectomy. Surg Laparosc Endosc 1994;4(2):146-8.

2. Li S, Gu L, Shen Z, Mao D, Khadaroo PA, Su H. A metaanalysis of comparison of proximal gastrectomy with doubletract reconstruction and total gastrectomy for proximal early gastric cancer. BMC Surg 2019;19(1):1-8.

3. Zheng L, Lu L, Jiang X, Jian W, Liu Z, Zhou D. Laparoscopyassisted versus open distal gastrectomy for gastric cancer in elderly patients: A retrospective comparative study. Surg Endosc 2016;30(9):4069-77.

4. Wang JB, Zhong Q, Chen QY, Lin GT, Liu ZY, Huang XB, et al. Well-designed retrospective study versus small-sample prospective study in research based on laparoscopic and open radical distal gastrectomy for advanced gastric cancer. Surg Endosc 2020;34(10):4504-15.

5. Chen X, Feng X, Wang M, Yao X. Laparoscopic versus open distal gastrectomy for advanced gastric cancer: A metaanalysis of randomized controlled trials and high-quality nonrandomized comparative studies. Eur J Surg Oncol 2020;46(11):1998-2010.
6. Yoshida K, Honda M, Kumamaru H, Kodera Y, Kakeji Y, Hiki $\mathrm{N}$, et al. Surgical outcomes of laparoscopic distal gastrectomy compared to open distal gastrectomy: A retrospective cohort study based on a nationwide registry database in Japan. Ann Gastroenterol Surg 2018;2(1):55-64.

7. Kim SH, Chung Y, Kim YH, Choi SI. Oncologic outcomes after laparoscopic and open distal Gastrectomy for advanced gastric Cancer: Propensity score matching analysis. J Gastric Cancer 2019;19(1):83-91.

8. Li Z, Shan F, Ying X, Zhang Y, Jian-Yu E, Wang Y, et al. Assessment of laparoscopic distal gastrectomy after neoadjuvant chemotherapy for locally advanced gastric cancer: A randomized clinical trial. JAMA Surg 2019;154(12):1093-101.

9. Katai H, Mizusawa J, Katayama H, Morita S, Yamada T, Bando E, et al. Survival outcomes after laparoscopy-assisted distal gastrectomy versus open distal gastrectomy with nodal dissection for clinical stage IA or IB gastric cancer (JCOG0912): A multicentre, non-inferiority, phase 3 randomised controlled trial. Lancet Gastroenterol Hepatol 2020;5(2):142-51.

10. Chen G, Xu X, Gong J, Zhang G, Cao Y, Zhang L. Safety and efficacy of hand-assisted laparoscopic versus open distal gastrectomy for gastric cancer: A systematic review and metaanalysis. Zhonghua Wei Chang Wai Ke Za Zhi 2017;20(3):3205.

11. Wang H, Mou T, Chen H, Hu Y, Lin T, Li T, et al. Long-term outcomes of laparoscopy-assisted distal gastrectomy versus open distal gastrectomy for gastric cancer: A 10-year singleinstitution experience. Surg Endosc 2019;33(1):135-44.

12. Li Z, Ji G, Bai B, Yu D, Liu Y, Lian B, et al. Laparoscopyassisted distal gastrectomy versus laparoscopy-assisted total gastrectomy with D2 lymph node dissection for middle-third advanced gastric cancer. Surg Endosc 2018;32(5):2255-62.

13. Qiu H, Ai JH, Shi J, Shan RF, Yu DJ. Effectiveness and safety of robotic versus traditional laparoscopic gastrectomy for gastric cancer: An updated systematic review and metaanalysis. J Cancer Res Ther 2019;15(7):1450.

14. Beyer K, Baukloh AK, Kamphues C, Seeliger H, Heidecke $\mathrm{CD}$, Kreis ME, et al. Laparoscopic versus open gastrectomy for locally advanced gastric cancer: A systematic review and meta-analysis of randomized controlled studies. World J Surg Oncol 2019;17(1):1-9.

15. Yamada T, Kumazu Y, Nakazono M, Hara K, Nagasawa S, Shimoda Y, et al. Feasibility and safety of laparoscopy-assisted distal gastrectomy performed by trainees supervised by an experienced qualified surgeon. Surg Endosc 2020;34(1):42935.

16. Zhou J, Du R, Zhang Q, Wang D. Laparoscopy-assisted pylorus-preserving gastrectomy versus laparoscopy-assisted distal gastrectomy for early gastric cancer in perioperative outcomes: A meta-analysis. Asian J Surg 2020;43(8):862-3.

17. Yao Z, Cui M, Xing J, Yang H, Zhang C, Zhang N, et al. Application of laparoscopy-assisted total gastrectomy in elderly patients $\geq 65$ years with gastric cancer. Zhonghua Wei Chang Wai Ke Za Zhi 2018;21(12):1396-402.

18. Hyung WJ, Yang HK, Park YK, Lee HJ, An JY, Kim W, et al. Long-term outcomes of laparoscopic distal gastrectomy for locally advanced gastric cancer: The KLASS-02-RCT randomized clinical trial. J Clin Oncol 2020;38(28):3304-13.

19. Li Z, Shan F, Ying X, Zhang L, Ren H, Li S, et al. Laparoscopic or open distal gastrectomy after neoadjuvant chemotherapy for advanced gastric cancer: Study protocol for a randomised phase II trial. BMJ open 2018;8(8):e021633. 
20. Goh PM, Alponat A, Mak K, Kum CK. Early international results of laparoscopic gastrectomies. Surgical endoscopy 1997;11(6):650-2.

21. Lin JX, Huang CM, Zheng CH, Li P, Xie JW, Wang JB, et al. Surgical outcomes after laparoscopy-assisted distal gastrectomy and open distal gastrectomy for patients with advanced gastric cancer: A case-control study using a propensity score method. Zhonghua Wai Ke Za Zhi 2016;54(10):755-60.

22. Nishimura S, Oki E, Tsutsumi S, Tsuda Y, Sugiyama M, Nakashima Y, et al. Clinical significance of totally laparoscopic distal gastrectomy: A comparison of short-term outcomes relative to open and laparoscopic-assisted distal gastrectomy. Surg Laparosc Endosc Percutaneous Tech 2016;26(5):372-6.
This is an open access article distributed under the terms of the Creative Commons Attribution-NonCommercial-ShareAlike 3.0 License, which allows others to remix, tweak, and build upon the work non-commercially, as long as the author is credited and the new creations are licensed under the identical terms

This article was originally published in a special issue, "Novel Therapeutic Approaches in Biomedicine and Pharmaceutical

Sciences" Indian J Pharm Sci 2021:83(6) Spl Issue “210-218” 